\title{
Engineering the Engineering Program: The Year of Discovery
}

\author{
Claudio da Rocha Brito \\ Science and Education Research Council \\ São Paulo, Brazil \\ drbrito@,copec.eu
}

Melany M. Ciampi

World Council on Systems Engineering and Technology Information

São Paulo, Brazil

drciampi@copec.eu

Victor F. A. Barros

Science and Education Research Council

Braga, Portugal

victor@copec.eu

\author{
Luis Amaral \\ Computer Graphics Center \\ Guimarães, Portugal \\ amaral@dsi.uminho.pt
}

\author{
Rosa Vasconcelos \\ University of Minho \\ Guimarães, Portugal \\ rosa@det.uminho.pt
}

\begin{abstract}
Retention is an issue that has been faced by many engineering colleges due to the difficulties and lack of knowledge about what it really is to be an engineer. The first 3 years of the course are particularly intense and hard. A way to overcome this period might be achieved by implementing a new kind of course, more enticing and dynamic. That is the idea of COPEC's engineering education research team, to embed a program with a more interesting activity for students in the first year. It is what has been named after "The Year of Discovery", a short-term workshop in order to show students the possibilities of performing as engineers in a global environment - a project developed for a private university, in order to decrease the retention rate in their engineering programs.
\end{abstract}

Keywords - Retention, project development, real world work, international skills, innovations.

\section{INTRODUCTION}

Currently, globalization has created a greater need for workers with higher levels of education and specific skills, in order to perform in advanced economies. Under skilled workers are disappearing, due to automation and low-cost labor market abroad. Nations worldwide recognize, particularly in the western part of the globe, that it is urgent to form a larger number of engineers with technical knowledge and soft skills.

Although engineering programs are full of important core subjects, it is necessary to innovate and find ways to embed the curricula with important topics to attend the current global trends. Once engineering skills are internationally portable, which leads to international mobility that engineering can easily provide and it is in fact a trend that is increasing. Intercultural skills, knowledge of languages and cultural prejudice management are very important topics, because opportunities are less and it is important to be able to adapt to any different cultural environment.

Many engineering colleges have been facing the retention issue due to the difficulties and lack of knowledge about what it really is to be an engineer. The first 3 years of the courses are particularly intense and hard. A way to overcome this period might be achieved by implementing a new kind of course, more enticing and dynamic. That is the idea of COPEC's engineering education research team, to embed a program with a more interesting activity for students in the first year. It is what has been named after "The Year of Discovery", a shortterm workshop in order to show students the possibilities of performing as engineers in a global environment - a project developed for a private university in order to decrease the retention rate in their engineering programs.

It is a 3 months period in the second semester of the $1^{\text {st }}$ year, when students have different classes, which are more dynamic due to the mix of site visits, lectures, project proposals, travel periods and project presentations. It is a very dynamic experience, which provides them a clear view of what it is to be an engineer and what their possibilities for the future are

The final goal of this project is to provide a sophisticated period for implementing integrated environments for teaching/learning systems. It is, in fact, a way to reduce the evasion of engineering courses, showing a glimpse of what it is to be an engineer and the wide varieties of opportunities worldwide. 


\section{COPEC: SCIENCE AND EDUCATION RESEARCH COUNCIL}

COPEC - Science and Education Research Council is a multi-disciplinary organization, leader in advanced science and its application to the development of technology serving society. It started its activities sixteen years ago and since then this organization has made a major contribution to the development of science and education, working to increase the best practices in several research fields.

Integration activities, promoted by COPEC, provide a qualified coordination and building partnerships because COPEC is an organization that brings together scientists who share the mission of promoting and developing science, technology and education.

The objectives of COPEC are to promote professionalism, integrity, competency, and education; foster research, improve practice and encourage collaboration in the different fields of sciences.

Contents, tools and services provided by COPEC, through courses, publications and consultations with national and international experts, contribute to the promotion of the professional who wants to be privy of the new achievements and the service of man to technology.

COPEC enjoys respect and recognition internationally, characterized by the open discussion, the free exchange of ideas, respectful debate, and a commitment to rigorous inquiry. Its IIE - International Institute of Education - is a bold and resilient source of innovation in higher education [1].

\section{CONTEMPORARY ASPECTS OF EDUCATION}

Work environment worldwide has changed drastically, and today millions of professionals are also unemployed, even in advanced economies. On the other hand, businesses in economically advanced countries claim that they are often not able to find workers with the required skills. It is a fact that this is a symptomatic dysfunction due to the structural changes that are transforming the nature of work and reshaping employment opportunities. This shows that organizations and policies are not keeping up with the changes in business practices and in new technologies, that are defining what kind of jobs will be created and where they will be located. So there is a need for companies to redefine how and where different tasks have to be carried out, requiring new skills and new employer and employee relationships [2].

It is also important to attempt that globalization has been expanding access to low-cost talent professionals and creating a greater need for workers with higher levels of education and specific skills in order to perform in advanced economies. Under skilled workers are disappearing due to automation and low-cost labor market abroad. In this world scenario, education and training should be seen as vital economic priorities by governments. However, it is still possible to observe the neglect of some nations, perhaps due to lack of political interest other than electoral.

Although governments need to invest in the entire system that builds workforce skills, in some places it is up to private initiatives to offer opportunities for young ambitious talented professionals, who can cooperate for a better future of generations to come. There is no better place than universities to offer these opportunities, pushed by the enterprises. It is important for nations to train highly skilled native-born citizens, as well as to attract highly skilled immigrants in order to be competitive in a global scale and assure a future for people [3].

Finally, government agents should be aware of the fact that if there is no production system, there will be no financial resources to maintain the social assistance system. This idea of an innovative office will help to generate more quality services to improve industry service, as well as the production system generating opportunities and jobs, which is a need everywhere in the world today [4].

\section{IV. “THE YEAR OF DisCOVERY" - THE COURSE}

The proposed course promotes and allows students to know what it is to be an engineer. It is a short-term workshop in order to show them the possibilities of performing as engineers in a global environment with the goal to decrease the retention rate in engineering programs.

It is a 3 months period in the second semester of the $1^{\text {st }}$ year, when students have different classes, which are more dynamic due to the mix of site visits, lectures, project proposal, travel periods and project presentations. It is a very dynamic experience, which provides them a clear view of what it is to be an engineer and what their possibilities for the future are.

Besides the proposal of a project, which students have to do, the course includes a short study period abroad, preferably in Europe. This period happens after the project proposal and before its presentation, ending in October before the tests period.

The period abroad includes Technical, Academic, Social and Cultural activities, all very important to have a real experience, however brief, and to understand a little about the lifestyle, history and culture of a country elected by COPEC education team.

All activities are performed within two weeks of intense work, generally in September. During this period, students also have lectures, visits to companies, universities, as well as social and cultural activities, which will provide students with a great experience and the discovery of a different world.

The period abroad can be done in more or less days, according to the needs of the course proposal for the period. Activities can be altered to fit the availability of organizations and people involved as well.

\section{METHOD}

It has three phases:

Phase 1 - when students have lectures of industry preferably and are challenged to make a project proposal in a specific engineering theme;

Phase 2 - when students go abroad for a short period; 
Phase 3 - when students present their project proposal to a group of invited professionals who evaluate them.

The course is designed to introduce the world of engineering to students and also to give them the opportunity to meet a new culture, explore several academic and business environments, develop cultural activities, as well as to explore the history and local public services where engineering plays an important role. The proposed course consists of an opportunity to improve the training of engineering students, providing them with an excellent experience, by knowing the practice of engineering in many sectors as well as an experience abroad.

\section{THE PERIOD ABROAD DETAILS}

The period abroad program includes lectures, visits to companies, universities, as well as social and cultural activities, which will provide students with a great experience and discover a different world.

The program can be done in more or less days, according to the availability of the group of students. Activities can also be changed to fit the goals of the course. It is in fact a very flexible part of the course. In fig 1 it is possible to see an example of a schedule designed for a group of students.

\section{FIG I. SCHEDULE FOR 2016/2017}

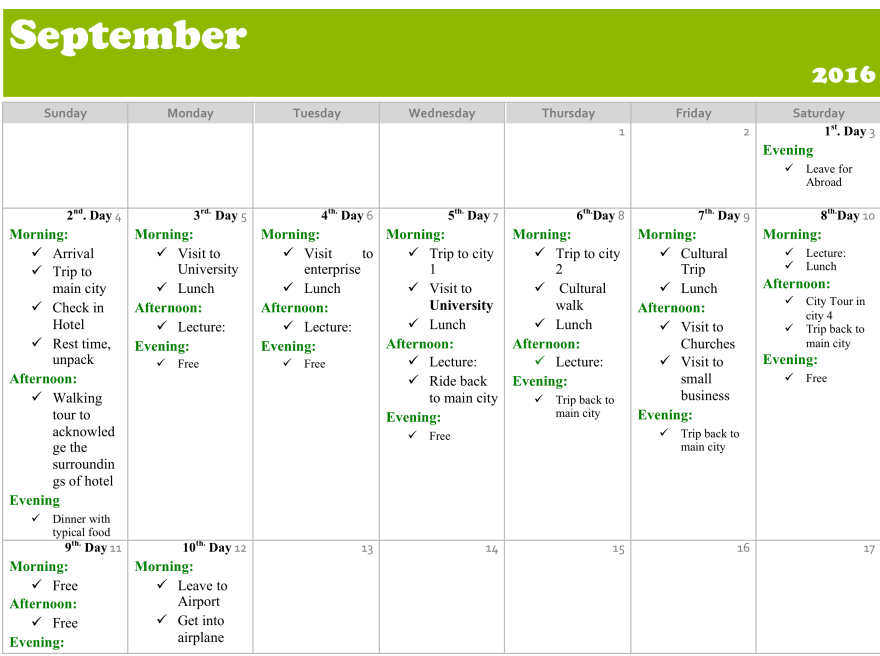

Within academic activities, students have classes and participate in activities in different universities.

Technical activities include visits to some companies of the visited country.

During social activities, students have the opportunity to visit some local meetings with other students in a friendly environment.

These cultural activities provide students with concepts of history and art, as well as their way of life, including guided tours, visit to museums and other related activities.

All proposed activities take place in a way that students can experience the educational environment, business, culture and lifestyle of the selected country.
The proposed program consists of an opportunity to improve the training of engineering students, providing them with an excellent experience abroad and to acknowledge the international career that an engineer can develop.

The program has the reputation of being demanding, rewarding, intense and provides a challenging educational environment by following high quality standards. Programming is developed to provide the participants also some free time to relax and enjoy the city and all it can offer.

Accommodations could not be better, students stay in comfortable hotels with all facilities, in downtown areas of the cities [5]

\section{SPeCIFIC OBJectives, GoAls And ExPECted Results}

The primary goal of the program is to stimulate curiosity and passion for the engineering profession. Provide to the engineering student an opportunity to experience different environments in the chosen profession.

Furthermore the program aims to:

- Improve academic skills and leadership;

- Learn and live in Different Cultures;

- Strengthen career goals;

- Search;

- Travel;

- Global Experience;

- New Opportunities;

- Enrichment of life [6].

The project goals are:

- Providing an international academic experience;

- Make the students feel what it is to be an engineer;

- Assist in the development of critical analysis;

- Provide an overall experience.

The expected outcomes of this extra academic class experience are:

- Dynamism for an undergraduate career;

- Long-term friendships;

- Technical skills and knowledge;

- Experiences of the different cultures and histories;

- Enrichment of life;

- Valuing the profession [7].

\section{CONCLUSIONS}

In the $21^{\text {st }}$ Century Universities are becoming the key role in local development. It is clear that along the history universities have become international organizations, not only in recruiting students from all parts of the world, but also through international research partnerships and providing student opportunities. No doubt that this role has become imperative for countries in order to keep up with the challenging educational and global research environment. The best universities attract the best students and better students make the university better.

The enhancement and promotion of students' formation quality, as well as employability, brings financial resources, increases teachers' quality and promotes the regional 
development, besides the future professional, no matter the field but mainly in engineering.

And finally no matter the political scenario of the country, governments must invest in Science and Technology for the sake of national economy and development in a global competitive environment that nations live.

This course in particular promotes the engineering programs, by combating the retention issue and providing students a glimpse of what it is to be an engineer and the possibilities of an international career.

\section{ACKNOWLEDGMENT}

This work has been financed by FEDER funds through the Competitivity Factors Operational Programme - COMPETE: POCI-01-0145-FEDER-007136 and POCI-01-0145-FEDER007043 and FCT - Fundação para a Ciência e Tecnologia within the Project Scope: UID/CEC/00319/2013.

\section{REFERENCES}

[1] http://www.copec.eu

[2] http://www.teachthought.com/learning/10-characteristics-of-ahighly-effective-le arning-environment/

[3] http://www.pewinternet.org/2014/04/17/us-views-of-technology-andthe-future/

[4] Brito, C. da R.; Ciampi, M. M.; Vasconcelos, R. M. C. F.; Amaral, L. A. M.; Barros, V. F. A. Engineering Impacting Social, Economical and Working Environment. In: American Society for Engineering Education Annual Conference, 120, Atlanta, 2013. 2013 ASEE Annual Conference Proceedings. Atlanta: ASEE, 2013.

[5] Brito, C. da R.; Ciampi, M. M.; Vasconcelos, R. M. C. F.; Amaral, L. A M.; Barros, V. F. A. Innovative on Demand International Engineering Programs. In: European Society of Engineering Education Annual Conference, 42, Birmingham, 2014. Educating Engineers for Global Competitiveness. Birmingham: SEFI, 2014.

[6] Ciampi, M. M.; Brito, C. da R.; Amaral, L. A. M.; Vasconcelos, R. M. C. F.; Barros, V. F. A. A Program Designed to Empower Engineering Educators. In: ASEE/IEEE Frontiers in Education Annual Conference, 44, Madrid, 2014. Opening Innovations and Internalization in Engineering Education. Madrid: FIE, 2014. p. 1925-9.

[7] Barros, V. F. A.; Ciampi, M. M.; Brito, C. da R.; Vasconcelos, R. M. C. F.; Amaral, L. A. M. Engineering Programs for Engineers - A global Higher Education Perspective. In: International Society of Engineering Education (IGIP) Annual Symposium, 43, Dubai, 2014. Engineering Education for a Global Community. Dubai: IGIP, 2014. p. 1039-42. 